HETEROCYCLES, Vol. 79, 2009, pp. 3 - 8. ๑ The Japan Institute of Heterocyclic Chemistry DOI: 10.3987/COM-08-S(D)Preface-2

\title{
Memorial Preface for Dr. John W. Daly: \\ A Retrospective on Our Collaboration on Batrachotoxin Chemistry
}

To my deepest regret, John Daly's visit to Japan on September 2005 would become the last time for me to see him. Never did I think that we would be forever separated from him. Whenever he visited us, as on his last trip to Japan, we shared delightful days, often talking till midnight about many things experienced on his expeditions, travels and so on. At that time he told us earnestly that he liked his research-activity at $\mathrm{NIH}$ and wished to continue laboratory work even after his $80^{\text {th }}$ birthday. In retrospect, I clearly remember that he took medicines, more than ten kinds, after every meal.

In taking the opportunity of writing this appreciation of John, I would like to describe the superior temperament he showed me through my pleasant recollections of the progress in my first collaboration with him.

At the end of 1966, a year after since the beginning of my study at NIH, Dr. B. Witkop, Chief of Laboratory of Chemistry in the National Institute of Arthritis and Metabolic Diseases, asked me to join the research program on very toxic secretion of Colombian frogs (The first report on scientific investigations by Drs. F. Märki and B. Witkop, 1963). The toxic material from the poison-arrow frogs, Phyllobates aurotaenia (5000 skins collected by M. Latham and John, 1966) were handed to me, along with the following information, 1) the toxin was an alkaloid, named Batrachotoxin, 2) it gave a positive response (blue color) with the modified Ehrlich test (p-dimethylamino-cinnamaldehyde), 3) it was suspected to consist of two components, and 4) it was fatally toxic in the case of the poison penetrating a wound on skin. Further, Dr. Witkop added the information, that he and John had just come back from a hospital visit to Latham then, recovering from being in a critical condition caused by small cut on frog-skinning work. She had just dodged the fate of a game animal being struck by a blow dart tip coated with this toxic material. It required great skill by Colombian Indians to safely prepare a blow dart carrying the toxic material. During my handling of the toxins, I felt my lips numbed sometimes in spite of paying particular attention not to wound myself. Considering the nature of the materials, we can imagine how tough it was to collect Phyllobates aurotaenia and their skinning in the jungle of Colombia. One day, after I had asked John to take me with him to the jungle for more frogs collecting, he just replied with a smile "Takashi! Have you ever touched a pistol?" I immediately recognized his wish not to 
take me there; how dangerous it was to skin collected frogs and that there could be many other threatening situations in the jungle. Certainly John was such a tough chemist in the jungle. He was always ready to apply his tasting test to distinguish venomous frogs. This typified his sincere attitude toward his research. I saw this even in the peaceful Nara Park of Japan. Suddenly he grabbed up a small frog and did the same test to its back. Afterwards, he simply mentioned that there was no toxin by his tasting test.

Dr. C. W. Myers, the American Museum of Natural History in N.Y. who often joined John to collect in the jungle, once commented, "John has a built-in compass". Obviously John's built-in compass performed excellently not only in the jungle but also, I felt, in various aspects of chemical investigation. An example was his finding of the specific blue coloration of Batrachotoxin resulting in the modified Ehrlich test, and which provided an accurate compass to develop a good separation of batrachotoxins of purity adequate to determine their structures.

After intensive examinations of chromatography on silica gel column for three months to replace the TLC separation earlier applied, the alkaloid material previously called Batrachotoxin could be clearly separated into two active components. Since both components on mass spectrometry showed the same ion, $\mathrm{m} / \mathrm{z}, 399$ $\left(\mathrm{C}_{24} \mathrm{H}_{33} \mathrm{NO}_{4}\right)$ observed as likely molecular ions, they were renamed as Batrachotoxin and Isobatrachotoxin. Since the frog venom was a very scarce, precious resource, Dr. Witkop suggested we put a priority on getting a single crystal of the venom, which seemed to be, through X-ray crystallography, our sole hope of elucidating the chemical structure. The first success came after half a year, June 15 1967, in the form of a very tiny needle-like crystal. However, this crystal was the $p$-bromobenzoate of a third congener, Batrachotoxinin $\mathrm{A}, \mathrm{M}^{+} \mathrm{m} / z, 417 \mathrm{C}_{24} \mathrm{H}_{35} \mathrm{NO}_{5}$, which was much less toxic and was negative for the Ehrlich test.

A month later, Dr. Witkop received a prompt report of the X-ray crystallography from Drs. J. and I. L. Karle of the Naval Research Laboratory. I clearly remember the moment when Dr. Witkop handed it to us. Immediately after John took a glance at the unfamiliar and complicated drawing of the frame figure of Batrachotoxinin-A p-bromobenzoate (Figure 1), he exclaimed, “This is a steroid!” However, I remained bewildered for a while. John showed here his excellent solid geometrical comprehension and his built-in compass. The frame construction was barely related to the usual chemical structure representations (see Figure 1). Moreover in this case, it was quite a unique and complicated steroid. Anyway, this was the first structure in our hands since the beginning of the chemical study and certainly encouraged us to proceed with further studies. 


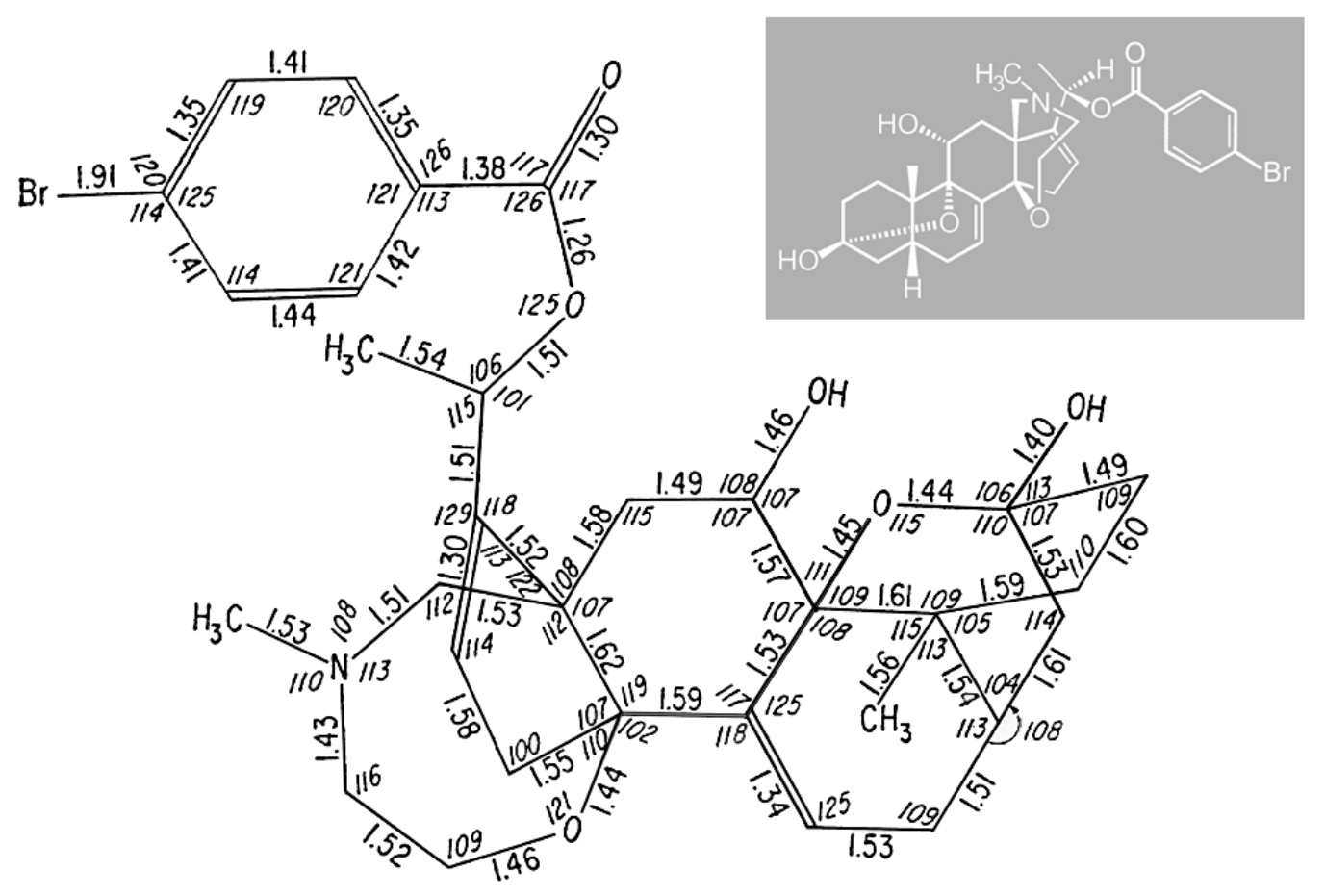

Figure 1. Bond lengths and angles of batrachotoxinin A p-bromo-benzoate

However the progress of our investigation stagnated for a year after this event. Most attempts to crystallize either of the batrachotoxins were unsuccessful. Although recrystallization of carbonate of Batrachotoxin afforded a prism-like crystal, it proved unsuited for X-ray crystallographic examination. Another reason for our lack of progress was a shortage of the purified samples. The amounts of the isolated materials from $\sim 5000$ P. aurotaenia frog-skins were as follows: Batrachotoxin $17 \mathrm{mg}$, Isobatrachotoxin (later renamed as Homobatrachotoxin) $16 \mathrm{mg}$ and Batrachotoxinin A $34 \mathrm{mg}$.

This was in the late 1960s and before the advent of the current powerful FT-NMR spectral techniques that nowadays have facilitated obtaining and interpreting of NMR spectra. Our proton NMR spectra $(\mathrm{CW})$ required overnight accumulation on a computer (Varian A60 equipped with a C1024 TIME AVERAGING COMPUTOR) with 40-50 scans being required for these samples). This was necessary to evaluate even the five methyl signals of Batrachotoxin. This time period was also before the introduction of chemical ionization, fast-atom bombardment, and other powerful mass spectral techniques now in use. Consequently a long period elapsed where overlooking the real molecular ion in a case of unknown samples was a likely possibility.

Only the double-focusing MS-9 mass spectrometer, the most advanced instrument at NIH during that time, continued to give us precious information, including an element-map. John worked very hard to master this titanic instrument with the assistance of Dr. H. M. Fales, occasionally working even on weekends, to acquire useful mass data for us. Furthermore he matched most peaks on an oscilloscope with manual control to obtain accurate masses to prepare an element-map. My role here was only rolling 
the handle of our "Tiger Calculator" to assist his work. His 'built-in compass' allowed him to learn exactly these complicated operations during this less computer-equipped age.

A turning point came when another look was taken at the mass spectrum of Batrachotoxinin A $p$-bromobenzoate, where twin molecular ions were observed as a weak but definite pair of signals $(\mathrm{m} / \mathrm{z}$ 599 and 601) on a noisy baseline. New attention was paid to these molecular ions, which looked to yield two noteworthy peaks by fragmentation. Those were the ion $p$-bromobenzoic acid $(\mathrm{m} / z, 200$ and 202) and the ion $\mathrm{m} / \mathrm{z}$ 399, the latter which had been observed as the likely molecular ions of the batrachotoxins as cited above. This fragmentation suggested that Batrachotoxin was possibly an ester of Batrachotoxinin A and some acid, and should show a higher molecule ion than $m / z$ 399. In practice, a mass-measured-peak $m / z$ 139, $\mathrm{C}_{7} \mathrm{H}_{9} \mathrm{NO}_{2}$, was picked up from the spectrum as the likely acid part of Batrachotoxin and consequently the real molecular weight was estimated as 538. After various trials of EI ionization of Batrachotoxin with John, we finally observed the real molecular ion, $\mathrm{m} / \mathrm{z} 538$, coming up from a noisy background but just for a moment. This was on a Saturday afternoon, June 22, 1968. We were very much pleased by this observation and shook hands with each other and then we patted the cool titan instrument AEI MS-9 all over. Especially for John, who had worked so hard to master its operation, this had to be one of the most impressive moments for him. Afterward John concentrated most of his attention on structural analysis by expanding his mass spectrometry studies, and these eventually led to the discovery of more than 800 alkaloids from other poison frogs.

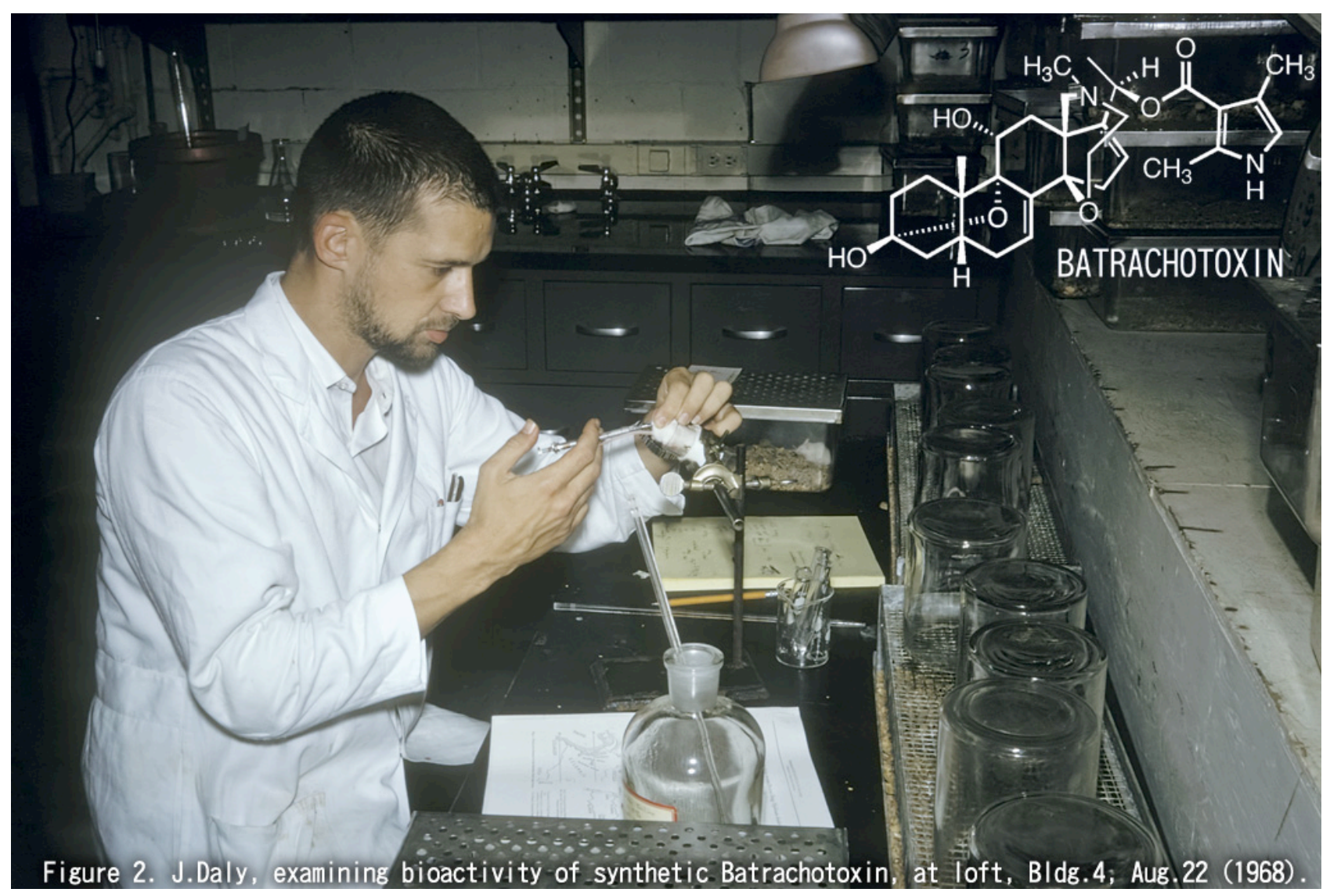


Proton NMR spectra applying solvent shifts between benzene and chloroform revealed the structure of the acid part of Batrachotoxin as 2,4-dimethylpyrrole-3-carboxylic acid (see Figure 2). It also confirmed 2-ethyl-4-methyl-pyrrole-3-carboxylic acid as the acid part of Isobatrachotoxin. Based on this new finding Isobatrachotoxin was renamed Homobatrachotoxin. Batrachotoxin was then synthesized two months later from natural Batrachotoxinin A. The next day, August 22 1968, the biological activity (LD50, SC mice) of the synthetic product was examined. Figure 2 is a photo of John taken by myself at that moment and now it becomes a most precious memory for us. When John obtained full biological activity, it meant completion of the first stage of his life's work on frog venom chemistry. Certainly we toasted it in that evening. In addition, the synthetic sample was confirmed in its identity with Batrachotoxin through ${ }^{1} \mathrm{H}-\mathrm{NMR}$ observation $(5 \mathrm{mg}$, accumulation of $\mathrm{CW}$-spectrum 200 times, each scan took $500 \mathrm{sec}$ ). Interestingly, this measuring time (close to $30 \mathrm{~h}$ ) became adequate 25 years later to obtain complete assignments for all of the proton and carbon signals of Batrachotoxin using a higher magnetic field FT-NMR spectrometer (JEOL GX-400, with the same sample size but using a micro cell).

Meanwhile in 1970, Dr. E. X. Albuquerque (Electrophysiologist, University of Maryland) revealed Batrachotoxin to be a potent and specific activator of sodium channels in collaboration with John.

In 1973, John and Myers collected in Colombia, a new larger Phyllobates frog that they named $P$. terribilis, ( 1 .5 inches length; cf. $P$. aurotaenia, smaller than 1 inch). This frog secretes twenty times larger amounts of the batrachotoxins and is too dangerous for the "taste test". For separation and purification of batrachotoxins from the skin extract of 1086 of these frogs, chromatography on a reverse-phase column (Merck, Lobar LRP-8) or a gel-filtration column packed with Sephadex LH-20 (GE, Dextran-Matrix) were mainly used. As the result, these separations yielded in total: Batrachotoxin (0.55 g), Homobatrachotoxin (0.39 g) and Batrachotoxinin A (0.37 g). Large amounts of the toxins have been widely distributed for various investigations of neuro-pharmacology through John's hand.

Our collaboration has continued with the alkaloid chemistry of these frogs of the family Dendrobatidae, $D$. histrionicus, D. auratus, and D. pumilio, over the years during my sojourns at NIH and even after my final return to Japan.

As mentioned above, I shared a lot of pleasant and memorable moments at NIH with John and relished the opportunity to see John Daly's passion for the science, his prominent talent, and also his sovereign humanity to his neighbors. It had been my personal desire to keep the friendship with John forever. Last March, to my deepest sorrow, it had turned out to be just my dream. The only word I can say now with his friends is as follows: 'May his soul rest in peace'. 
Finally, along with late John W. Daly, I would like to express my warmest gratitude to our common mentor Dr. B. Witkop who guided our Batrachotoxin chemistry to a fruitful result and my sincere thanks to Dr. T. F. Spande and many friends who fully supported and enriched my NIH life.

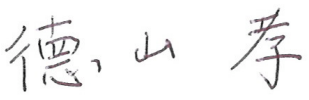

Takashi Tokuyama

Daido 2-8-16, Tennouji-Ku, Osaka, 543-0052, Japan E-Mail: byf02451@nifty.com

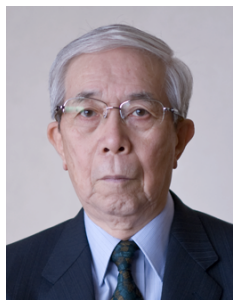

Takashi Tokuyama was born in 1932 in Osaka. He graduated from Osaka City University, Faculty of Polytechnics, in 1954 and became Assistant Professor in 1955. He received Ph. D. in 1961 from the same university under the direction of Professor Takeo Sakan working on tryptophan metabolites and spent three years $(1965$ 1968) at NIH (National Institute of Health) as a visiting associate with Dr. Bernhard Witkop. After his first visit above he sojourned at NIH in 1971 and 1973 as a visiting scientist. After his retirement from Professor of Faculty of Science, Osaka City University, he visited NIH as a courtesy associate for collaboration with Dr. John Daly in 1995. 